\title{
Reflexiones sobre la implementación jurídica del principio de "participación económica de los asociados» en las cooperativas cubanas
}

\author{
(Reflections about the juridical implementation \\ of the principle of «the members' economic participation» \\ in the Cuban cooperatives)
}

Orestes Rodríguez Musa ${ }^{1}$

Orisel Hernández Aguilar²

Universidad de Pinar del Río (Cuba)

Sumario: I. Introducción. II. El principio de «participación económica de los asociados»: generalidades. III. El principio de "participación económica de los asociados»: estado de su implementación jurídica en Cuba. III.1. Regulación legal. III.2. Dimensión práctica en las Cooperativas No Agropecuarias. IV. A modo de conclusiones. V. Bibliografía. VI. Legislación.

Summary: I. Introduction. II. The principle of "the members' economic participation»: generalities. III. The principle of «the members' economic participation»: state of their juridical implementation in Cuba. III.1. Legal regulation. III.2. Practical dimension in the Non Agricultural Cooperatives. IV. By way of conclusions. V. Bibliography. VI. Legislation.

Resumen: Creciente resulta el debate sobre el cooperativismo en Cuba, en tanto la actualización del modelo socioeconómico nacional renueva el interés por estas peculiares formas de empresa. Como parte de este proceso, la optimización de la regulación y aplicación del principio de «participación económica de los asociados» en las Cooperativas No Agropecuarias ha ganado especial importancia, pues su materialización se ha visto afectada por distintos factores —objetivos y subjetivos - que han dado lugar a conductas desviadas

1 Doctor en Ciencias Jurídicas, Profesor de Derecho Constitucional y Derecho de Cooperativas, Departamento de Derecho, Facultad de Ciencias Sociales y Humanísticas, Universidad de Pinar del Río, Cuba. E-mail: musa@upr.edu.cu

2 Doctora en Ciencias Jurídicas, Profesora de Historia General del Estado y el Derecho y Derecho Romano, Departamento de Derecho, Facultad de Ciencias Sociales y Humanísticas, Universidad de Pinar del Río, Cuba. E-mail: oriselha@upr.edu.cu 
de la identidad cooperativa. Por tal motivo, este trabajo se propone aportar algunas valoraciones teórico/prácticas que contribuyan a revertir esta situación. rias

Palabras claves: participación económica, Cooperativas No Agropecua-

Abstract: Increasing it is the debate on the cooperativism in Cuba, as long as the upgrade of the national socioeconomic pattern renovates the interest for these peculiar enterprise forms. As part of this process, the optimization of the regulation and application of the principle of «the members' economic participation» in the Non Agricultural Cooperatives it has won special importance, because their materialization has been affected by different factors -objectives and subjective - that have given place to deviated behaviors of the cooperative identity. For such a reason, this work intends to propose some theoretical and practical valuations in order to contribute to revert this situation.

Keywords: economic participation, Non Agricultural Cooperatives 


\section{Introducción}

Creciente resulta el debate sobre el cooperativismo en Cuba. En la Isla se perfilaron y potenciaron, sobre todo a partir de la década de los años 70, formas de cooperativización, con carácter exclusivamente agropecuario, como las Cooperativas de Créditos y Servicios (CCS), las Cooperativas de Producción Agropecuaria (CPA) y -a partir de los años 90- las Unidades Básicas de Producción Cooperativa (UBPC); pero los Lineamientos de la Política Económica y Social del Partido y la Revolución de abril de 2011 (VI Congreso del Partido Comunista de Cuba 2011), renuevan el interés por estas peculiares formas de empresa desde una perspectiva más general en cuanto a sus potencialidades de impacto en la vida socioeconómica del país.

Estos Lineamientos, actualizados por el último Congreso del Partido junto a otros documentos aprobado (VII Congreso del Partido Comunista de Cuba 2016) y ratificados por la Asamblea Nacional del Poder Popular - máximo órgano de poder del Estado- para guiar el proceso de actualización del modelo socioeconómico nacional, le confieren un importante rol a las cooperativas en la aspiración de diversificar los sujetos económicos que operan en el país y de elevar la productividad del trabajo.

Sobre esta base, se abrió una nueva fase, con carácter experimental y por ende en constante perfeccionamiento, encaminada a expandir las cooperativas hacia otros sectores de la economía nacional además del agropecuario, para lo cual se aprobaron un conjunto de disposiciones normativas publicadas en la Gaceta Oficial No. 053 Extraordinaria de 11 de diciembre de 2012.

Como parte del proceso de evaluación y corrección de este experimento, la optimización de la regulación y aplicación del principio de «participación económica de los asociados» en las Cooperativas No Agropecuarias (CNA) ha cobrado especial importancia, como queda explicitado en las más recientes intervenciones de las autoridades del país encargadas de implementar lo dispuestos en los Lineamientos. Por tal motivo, oportuno resulta aportar algunas valoraciones teórico/prácticas que contribuyan a avanzar correctamente en esta dirección.

\section{El principio de «participación económica de los asociados»: generalidades}

No resulta ocioso reiterar, que entre los principios cooperativos que utiliza la Declaración sobre la Identidad Cooperativa (ACI 1995) para 
delinear la institución, el tercero de ellos sienta las pautas generales para el régimen económico entre los asociados y la cooperativa:

«Los asociados contribuyen equitativamente a la formación del capital de su cooperativa y lo administran democráticamente. Por lo general, al menos una parte de ese capital es propiedad común de la cooperativa. Los asociados suelen recibir una compensación limitada, si acaso alguna, sobre el capital suscripto como condición para asociarse. Destinan los excedentes a todos o alguno de los siguientes fines: el desarrollo de la cooperativa, posiblemente mediante la constitución de reservas de las cuales una parte al menos debe ser indivisible; la distribución a los asociados en proporción a sus operaciones con la cooperativa y el apoyo a otras actividades aprobadas por los asociados».

Este principio orienta sobre la manera en que los asociados deben invertir en sus cooperativas y manejar sus resultados económicos. Desde este punto de vista, esta forma de empresa es especialmente sui géneris, ya que funciona de manera que el capital sirve a la organización y no la domina.

Como consecuencia de la actividad económica se generan excedentes ${ }^{3}$. Por razones éticas y también muchas veces por disposición legal, al menos una parte importante de ellos no puede ser distribuida entre los asociados a ningún título, ni acrecentarán sus aportaciones individuales; sino que conformarán el patrimonio común de la entidad, reflejo de lo que se ha logrado en colectivo y para disfrutarlo en este concepto 4 .

La apropiación y disfrute individual de los excedentes no constituye el fin de la asociación cooperativa, en tanto su objetivo no es recompensar el capital, sino satisfacer las necesidades económicas, sociales y culturales de sus asociados y de su comunidad. Por ello su finalidad se ha considerado «pública y de interés social» (Bastidas-Delgado 2009, 4), tanto que los ordenamientos jurídicos garantizan universalmente protección tributaria a las cooperativas.

3 Estos se definen como «sobrante del producto de las operaciones totales de la cooperativa, deducidos los costos y los gastos generales, las depreciaciones y provisiones, después de deducir ciertos porcentajes para fondos especiales del producto de las operaciones totales» (Bastidas-Delgado 2009, 4).

${ }^{4}$ El excedente repartible debe ser aquel que proviene de la diferencia entre el costo y el precio de los servicios prestados a los socios; aquel que no provenga de esta fuente será destinado a una reserva especial. También conforman habitualmente estos fondos irrepartibles, cualquier otro bien o derecho otorgado a la cooperativa a título gratuito (ACl 2009, artículos 8 y 49). 
Además, si la cooperativa dejara de existir, el capital colectivo no suele dividirse entre los asociados, sino que es trasladado al organismo de integración al cual pertenecía, a las cooperativas de la comunidad, o se coloca en función de la educación y el fomento cooperativo, dependiendo de la legislación de que se trate (ACI 2009, artículo 90).

En cuanto a la ausencia de ánimo de lucro, las cosas resultan menos claras cuando la empresa percibe ingresos de terceros, es decir, de personas que no son sus socios, algo cada vez más frecuente debido a la crisis del carácter mutualista de la cooperativa (Cano López 2008, 75-77; Kaplan de Drimer 2000, 167-175); o cuando los excedentes son plusvalías que resultan de trabajadores no asociados. En ambos casos, «si los asociados que no produjeron esos excedentes llegasen a apropiarse de ellos, estarían actuando con lógica capitalista» (Bastidas-Delgado 2009, 5). Ante esta problemática, se recomienda se destinen a quienes los favorecieron a través de actividades educativas, de apoyo al movimiento cooperativo u otras de carácter social (ACI 2009, artículos 8 y 49).

\section{El principio de «participación económica de los asociados»: estado de su implementación jurídica en Cuba}

Las reflexiones que se ofrecen a continuación confrontan la dificultad de operar sobre la base del marco legal del cooperativismo cubano el cual carece de una legislación general unificadora y armonizadora del sector, obligando a tratar con una pluralidad de normas, dispersas (algunas con carácter experimental), y una diversidad de formas que están fracturadas entre lo agropecuario y lo no agropecuario.

A fin de ordenar la exposición que sigue, se aborda primero el estado actual de la regulación del principio de preferencia en las normas vigentes para las distintas figuras cooperativas del país y, luego, se trata la cuestión de la implementación práctica del principio, fundamentalmente, en la provincia de Pinar del Río.

\section{III.1. Regulación legal}

La presencia de este principio transversaliza a las previsiones legales contenidas en la Ley No. 95, De Cooperativas de Producción Agropecuaria y de Créditos y Servicios, de 2 de noviembre de 2002 (L95/02); el Decreto-Ley No. 305, De las Cooperativas No Agropecuarias de 15 de noviembre de 2012 (DL305/12); el Acuerdo No. 5454 del Comité 
Ejecutivo del Consejo de Ministros, contentivo del Reglamento General de las Cooperativas de Producción Agropecuaria (RG-CPA/05) y del Reglamento General de las Cooperativas de Créditos y Servicios (RGCCS/05), de 17 de mayo de 2005; el Decreto No. 309, Reglamento de las Cooperativas No Agropecuarias de Primer Grado, de 11 de diciembre de 2012 (D309/12); y la Resolución No. 574 del Ministerio de la Agricultura, Reglamento General de las Unidades Básicas de Producción Cooperativa, de 13 de agosto de 2012 (R574/12).

La primaria cuestión de las aportaciones de los socios tiene cuatro formas diferentes de configurarse en el país, según el tipo de organización cooperativa de que se trate.

En las CPA se materializó con la contribución en tierras, demás bienes agropecuarios, instalaciones, medios culturales, recreativos y otros bienes (L95/02, artículo 32). A los socios que realizan estas contribuciones, la ley les denomina "aportadores» (L95/02, artículo 58), vocablo mediante el cual - a criterio de los autores - el legislador demerita el valor del trabajo de sus cónyuges, hijos, demás familiares y otros trabajadores que también son admitidos como asociados, en tanto la labor de estos constituye aportes no dinerarios, pero susceptibles de valoración socioeconómica. A ello debe sumarse el hecho de que valorar como «aportación» los bienes referidos resulta incorrecto, toda vez que la naturaleza del negocio jurídico que en este caso acontece es, en realidad, un "real acto de compraventa efectuado a través de diferentes formas de pago (L95/02, artículos 47 y 48) —al contado, a plazos o por una pensión vitalicia-» (Fernández Peiso 2005, 86).

En las CCS, los referidos aportes están dados por un por ciento del valor de la venta bruta de la producción comercializada por cada productor a las entidades acopiadoras en el Mercado Agropecuario y otros mercados, según lo acordado en la Asamblea General, lo cual se destina a la formación de un fondo colectivo (L95/02, artículo 49). Por tanto, el momento en que se concreta el aporte varía respecto a las CPA, toda vez que este se verifica como una contribución de sus miembros, no para la constitución de las cooperativas, sino para el aumento del patrimonio de estas (García Müller 2016, 39).

El régimen de aportaciones en las UBPC no alude expresamente a la cuestión tratada, pero también puede considerarse posterior a su constitución, ya que a estos asociados no se les exige contribución alguna al momento de constituirse (R574/12, artículo 11), sino que esta resulta de los ingresos totales obtenidos con su trabajo durante el ejercicio económico. Tal contribución se destina luego al pago o amortización del crédito utilizado para adquirir los bienes que fueron necesarios para su constitución, para el cumplimiento de las obligaciones adquiri- 
das producto de los créditos bancarios recibidos, y demás pagos que a viene obligada la entidad (R574/12, artículo 36, apartado 1).

Al respecto, la regulación más completa se encuentra en el Decreto Ley que ordena las CNA, en tanto se exigen que estas cuenten, al momento de su constitución, con un capital de trabajo inicial, integrado por el aporte dinerario que realizan los socios y por los créditos bancarios que se otorguen con ese objetivo (DL305/12, artículo 21). Además, se deja sentado que los socios, con independencia de cualquier otro aporte que hayan realizado, están en la obligación de participar con su trabajo (DL305/12, artículo 23).

Las diferencias existentes en cuanto a las exigencias relativas a las referidas aportaciones, se justifican por el tipo de actividad económica que cada forma cooperativa está llamada a realizar. Así, por ejemplo, resulta más apremiante la presencia de un capital inicial en las cooperativas cuya finalidad es la producción, que en aquellas que se encaminan a la prestación de servicios auxiliares a los productores. En este mismo sentido puede incidir la diversidad en el origen de los bienes que integran los patrimonios de dichas entidades, ya que encontramos regímenes de arrendamientos, usufructos y compraventas, incluso, mediante crédito bancario.

En cuanto a la utilización y distribución de los excedentes de las cooperativas, sabido es que como regla suele atenderse primero la deducción de determinados montos que se asignan a fondos y reservas (García Müller 2016, 88), u otras exigencias de las normas generales y/o internas. También en este particular se aprecia una disparidad al interior del sector en el país.

En tal sentido, se observa que en las CPA, cuando hayan liquidado totalmente el pago de los bienes aportados por los cooperativistas, y constituido más de la mitad de la reserva para cubrir contingencias, pueden distribuir 50\% o más de las utilidades, llegando hasta un 70\% cuando la hayan completado (L95/02, artículo 51 y RG-CPA/05, artículo 48). La forma de distribución de estas utilidades es una parte para el fondo de operaciones, otra para el fondo socio-cultural, y otra para distribuir entre los cooperativistas (L95/02, artículo 47).

En las CCS, si el saldo es favorable después de cubrir la reserva para contingencias y efectuados todos los pagos por créditos, tributos y otras deudas del período correspondiente, las utilidades se destinan a crear un fondo de desarrollo, estimular a los trabajadores, contribuir con el desarrollo económico y social de la comunidad, efectuar acciones a favor del medio ambiente, y realizar otros gastos que acuerde la Asamblea General para beneficio colectivo (L95/02, artículos 56 y 57). En estas cooperativas, sus miembros solo reciben los beneficios que se 
derivan de la gestión del fondo común, como lo dispone el artículo 54 de la Ley 95/02.

En el caso de las UBPC, las utilidades obtenidas al cierre del ejercicio económico se destinan para la Reserva de Pérdidas y Contingencias un mínimo del $2 \%$ de las utilidades reales del ejercicio y hasta el límite establecido en la legislación financiera vigente. De la utilidad neta obtenida, la Asamblea General determina la parte a distribuir entre los miembros y otros posibles destinos, como pueden ser, la adquisición de activos fijos y medios de rotación, construcción de viviendas, construcción de instalaciones productivas y sociales, y estimulación, siempre que no existan otras obligaciones prioritarias (R574/12, artículo 36). Entre estas últimas figuran las pérdidas de años anteriores que no puedan ser cubiertas con la Reserva para Pérdidas y Contingencias, a las cuales deben destinar como mínimo el $50 \%$ de las utilidades obtenidas, para ir eliminando dichas pérdidas (R574/12, artículo 37).

Por último, en las CNA, si estas hubiesen pagado íntegramente los bienes que le hayan sido vendidos y constituido más de la mitad de la reserva para cubrir contingencias, puede repartir más del $50 \%$ de las utilidades, hasta llegar a un $70 \%$ cuando haya completado dicha reserva. La distribución del fondo constituido según el por ciento de utilidades a distribuir, se realizará según la escala dispuesta en el Reglamento. La diferencia con el $100 \%$ de las utilidades que no se distribuyen a los socios, se destinan al fondo de operaciones, inversiones, actividades socioculturales, incrementar el fondo de contingencia y otros, según se apruebe en los estatutos (D309/12, artículo 57).

Además de la aludida disparidad existente en las regulaciones ordenadoras de esta materia, se aprecian imperfecciones y omisiones a la hora de manejar la terminología relativa a estas operaciones. Por ejemplo, las reservas se confunden nominalmente con los fondos $(V$. gr.: RG-CCS/05, artículo 56), o se omite su creación, aunque claramente los recursos se asignan a actividades susceptibles de ser denominadas de esta manera (V. gr.: R574/12, artículo 36). Todo ello no contribuye a la transparencia en las actuaciones, en tanto constituye un factor de desinformación para los propios asociados.

En cuanto a las formas y momentos fundamentales en que se efectúa la distribución de los excedentes, pueden diferenciarse dos: los anticipos o beneficios de otro tipo que reciben los socios a lo largo del ejercicio, y la distribución que se realiza al final de este. Al respecto se ha señalado que la retribución ex ante del retorno puede hacerse mediante la entrega de bienes y servicios a los asociados, que en las cooperativas de producción se materializa como anticipo, y como un ahorro de gastos si se tratara de cooperativas de servicios. En cuanto 
al retorno final, puede complementarse a posterioridad con otras actividades y servicios como educación, capacitación técnica, etc. (García Müller 2016, 107).

En Cuba, los anticipos se prevén como la forma típica de la retribución ex ante, que solo tiene una excepción en las CCS. Así pues, el artículo 44 del RG-CPA/05, el artículo 41 del R574/12 y los artículos del 60 al 62 del D309/12 disponen las reglas para su determinación y su distribución. Al respecto, conviene señalar que en todos los casos se consagra el principio de que la distribución estará en función de los resultados finales de la producción y de la cantidad y calidad del trabajo realizado.

A pesar del carácter de anticipo que le confieren las disposiciones jurídicas generales a estas compensaciones, el profesor Fernández Peiso $(2005,87)$ apunta que en «esta calificación de anticipo, también están presentes carencias técnico conceptuales en tanto el anticipo societario constituye una retribución a cuenta, deducible de las resultas finales del trabajo o servicio cooperativizado, no como ocurre con el denominado anticipo, en las cooperativas nacionales, que constituye una retribución de igual naturaleza que el salario». Esto es atribuible a la determinación fija que hacen las regulaciones internas de las sumas que cada cooperativista ha de devengar en concepto de "anticipo», sin que se considere el estado contable de la cooperativa en cada momento.

En resumen, se puede sostener que persiste la diversidad en la forma de manifestación del principio de «participación económica de los asociados» dentro del sector cooperativo en Cuba, siendo en esta materia la regulación de las CNA la más completa. En todo caso, es común la disposición de que el monto de los retornos sea decidido - en última instancia - por la Asamblea General, libertad que pudieran ser mejor aprovechada por estos órganos para establecer, en sus normas internas, sistemas de distribución más coherentes con la naturaleza cooperativa.

\section{III.2. Dimensión práctica en las Cooperativas No Agropecuarias}

Existen dos razones que justifican la necesidad de ahondar en la implementación del principio de "participación económica de los asociados» en el caso de las CNA, más allá de lo que al respecto pueden dictar las disposiciones legales vigentes. En primer lugar es pertinente porque estas nuevas formas cooperativas - a criterio de los autoresson las llamadas a impulsar la evolución del modelo cooperativo cubano hacia un estadío superior por la importancia que se les ha otorgado dentro del proceso de actualización del modelo socioeconómico 
cubano (VII Congreso del Partido Comunista de Cuba 2016-b, numerales 120 y 158 al 167). En segundo orden, porque las alusiones a algunas aristas de este principio se han reiterado en las intervenciones públicas de las autoridades que en el país monitorean las novedades del sector.

En lo fundamental la exposición que sigue se sustenta en las informaciones sobre los resultados del proceso de expansión de las cooperativas en Cuba que - bien directamente o a través de los medios oficiales de prensa- han ofrecido regularmente la Comisión de Implementación de los Lineamientos (Tristá Arbezú, 2015) y otras autoridades públicas; los estudios realizados en torno a las CNA por especialistas de distintas áreas del conocimiento ( $V$. gr.: Piñeiro Harnecker 2014 y Vuotto 2015); y alguna información sistematizada sobre las CNA de la provincia de Pinar del Río, bien de los legajos del Registro Mercantil de la provincia, mediante encuestas aplicadas a los socios y de otros documentos a los que se tuvo acceso (Rodríguez Musa 2017, 112-129).

Si bien en la constitución de las CNA se siguió, con apego a la ley, el principio de referencia al momento de realizar los aportes al capital de trabajo inicial, este acto estuvo mediado por un elemento condicionante. Se trata de la creación de estas entidades con importantes carencias en la capacitación a sus miembros (Rodríguez Musa y Rivera Gort 2015, 195-222) y, en varios casos, producto a la inducción desde el Estado (Vuotto 2015, 17). Con ello no solo se laceró la voluntariedad que distingue universalmente a estas formas asociativas, sino que además conllevó a la adopción de decisiones inconscientes, erradas o infundadas sobre otros múltiples aspectos igualmente vitales para el desempeño cooperativo, entre los que figura la previsión en los estatutos del sistema de distribución de los excedentes ${ }^{5}$.

Una vez que se comprende el carácter esencial de la consciencia de los potenciales socios en el acto de constitutivo de la cooperativa, no resulta extraño encontrar en el actual debate nacional referencias a la

5 En la encuesta practica a 48 socios de las CNA de la provincia, 24 respondieron que NO a la pregunta de si «¿Recibió alguna asesoría, capacitación u orientación en materia de cooperativas antes de tomar la decisión de asociarse?» (Rodríguez Musa 2017, anexo 4). No obstante, se ha insistido por directivos nacionales en que «...la preparación debe anteceder al cambio de modalidad y donde los trabajadores no hayan sido debidamente instruidos y asesorados, no se puede formar una cooperativa» (Castro \& otros 2015). Por tanto, «...se trabaja en la confección de un programa de preparación acerca de los principios de funcionamiento de las cooperativas, con prioridad para sus directivos, donde se aborden temas como la gestión de negocios, el sistema de contabilidad y la organización del sistema de control interno» (Martínez Hernández 2016). 
inadecuada planificación y gestión del retorno cooperativo, ya sea por medio de los anticipos o al final del ejercicio de cada año.

Debe comprenderse que estas reflexiones se insertan en un panorama en el que ha existido una elevación del nivel de satisfacción de los trabajadores implicados en el experimento de cambio de forma de gestión - constatable también en la provincia de Pinar del Río6 - en lo tocante al incremento de sus beneficios económicos con respecto a los salarios anteriormente percibidos mientras la entidad funcionaba como parte del sistema estatal (Tristá Arbezú 2015). A ello ha de añadirse que, como apunta Piñeiro Harnecker, los medios han difundido «la percepción estrecha y cortoplacista de las cooperativas como una forma empresarial para aumentar el ingreso de las personas que se hacen socios» (Piñeiro Harnecker 2014, 17), arraigando un enfoque lucrativo en la opinión pública que trasciende hacia el funcionamiento diario de estas entidades.

Así pues, la escasa conciencia cooperativa de muchos asociados, unido al relativo aumento de sus ingresos y la ponderación en la conciencia social del enfoque lucrativo, conspiran en muchos casos contra una previsión equitativa de los términos del retorno. Esto termina por explicitarse en los estatutos, en los cuales se aprecian tanto concepciones erradas de la naturaleza del anticipo, como regulaciones oscuras de las que no es posible colegir el sentido de lo plasmado.

Antes de abordar el contenido de estas normas internas, conviene precisar que desde los documentos referenciales elaborados en pos de coadyuvar a su adecuada formulación, se comenzó a gestar la desviación respecto a la idea originalmente asumida por el legislador. Para ilustrar, sirva el artículo 60 del D309/12, donde se advierte que «los anticipos de las utilidades a los socios serán en efectivo, bienes o servicios»; sin embargo, entre las Indicaciones Metodológicas dirigidas por la Dirección de Notarías y Registros Civiles del Ministerio de Justicia a los notarios que elaboraron las escrituras de constitución de las CNA, se consignó que «los anticipos de las utilidades a los socios serán en efectivo (además, según determinen, pudiera ser en bienes o servicios)» (Pérez Díaz 2013), dándole clara preferencia al «efectivo» - con una interpretación restrictiva de la norma- sobre las otras formas de

6 En encuesta practicada recientemente por la Comisión Económica de la Asamblea Provincial del Poder Popular en Pinar del Río a 160 de los socios de las CNA, «el 86.6\% se sienten satisfechos, solamente el $13.3 \%$ está medianamente satisfecho, y resulta muy significativo que nadie declaró sentirse insatisfecho en la nueva forma de gestión» (Comisión de Asuntos Económicos de la Asamblea Provincial del Poder Popular en Pinar del Río 2016). 
materializar el anticipo. Ello desembocó, en el caso de la provincia de Pinar del Río, en que todos los estatutos adoptados por las CNA, se sufre esta limitación en el sistema de distribución de anticipos (Registro Mercantil, Pinar del Río).

Otra confusión, que no es atribuible exclusivamente a los asociados, es la relativa a la identidad entre salario y anticipo. En las citadas Indicaciones Metodológicas, cuando se propone el artículo relativo a la forma de cálculo del anticipo, si bien se reproduce la fórmula del Reglamento General, acto seguido se yerra al señalar que "Se calcula el anticipo mínimo a partir de la estructura de la escala salarial vigente, entre las diferentes categorías se le aplicaría esa estructura» (Pérez Díaz 2013). Aunque el documento solo planteó una idea a considerar, en un contexto de limitado conocimiento del fenómeno cooperativo, tal sugerencia dio paso a su copia acrítica generalizada. De hecho, siete de las doce CNA de Pinar del Río, en sus estatutos originales dispusieron sumas fijas a devengar en el mes por los socios, en concepto de anticipo. Las cinco restantes no se excluyen porque lograran planificar reales anticipos, sino porque el nivel de ambigüedad de los enunciados estatutarios no permite conocer con claridad el criterio asumido (Registro Mercantil, Pinar del Río).

En resumen, estas insuficiencias son una consecuencia de un proceso para la elaboración y aprobación de los estatutos donde el espacio para la información, la iniciativa, la participación y el debate de los socios en torno a sus necesidades, fue ocupado por el formalismo, el dirigismo, las proformas y los rígidos cronogramas a cumplimentar. Todo ello ha dado lugar a que — como se verá a continuación- muchos de los estatutos de las CNA de Pinar del Río hayan sufrido alguna modificación (Registro Mercantil, Pinar del Río).

No obstante, de las doce CNA de la provincia solo seis han modificado sus estatutos en torno al asunto que nos ocupa, de manera que cabe presumir que las otras seis continúan devengando montos fijos mensuales, cual si fueran entidades estatales. De las cooperativas que modificaron sus normas en este sentido, cuando menos resulta llamativo que, habiendo sido constituidas todas ellas en 2013, las modificaciones en un apartado tan sensible para los socios, tengan fechas no siempre inmediatas a la constitución como 2014 (en dos de ellas), 2015 (en tres) y 2016 (en la que resta). Además, solo en cuatro de estos casos se adopta una modalidad de cálculo de la participación económica del socio en función de las utilidades disponibles y las características de la labor que realiza.

Tomando el caso de la provincia estudiada como botón de muestra, resulta fácil suponer que las limitaciones estatutarias mencionadas 
contribuyen a las desviaciones de la idea original para el desempeño de las cooperativas. Tales desviaciones se han concretado en «apropiación indebida de recursos y de ingresos; ( ) hechos de corrupción; cooperativas que funcionan como empresas privadas» (Cuba Debate 2017); y casos de CNA donde entre el que menos gana y el que más gana la diferencia es de catorce veces ${ }^{7}$.

A la vista de estas irregularidades, el Jefe de la Comisión de Implementación y Desarrollo anunció que se está trabajando en ajustes normativos que regulen los límites de ingresos, mínimo y máximo entre el que menos gana, y el que más gana dentro de la cooperativa, de tal forma que entre el que menos gana y el que más gana no haya una diferencia más grande de tres veces ${ }^{8}$.

La pertinencia de las regulaciones anunciadas es incuestionable. No obstante, la imposición de límites a la desproporción en la distribución de los beneficios, debe venir acompañada de otras medidas que ayuden a rectificar la causa de fondo que da origen a estas desviaciones. La cuestión central sigue siendo la misma: la necesidad de entender y proyectar jurídicamente las cooperativas desde su naturaleza de servicio a los asociados y a la comunidad. En tanto subsistan las incomprensiones al respecto, consciente o inconscientemente, subsistirán también las incoherencias prácticas con la identidad cooperativa.

A modo de síntesis, se puede afirmar que el estado actual del principio de «participación económica de los asociados» en las CNA es resultado de varios factores -objetivos y subjetivos - que han incidido en su materialización. Las imprecisiones existentes en las regulaciones - externas e internas - al respecto, han dado lugar conductas desviadas del espíritu cooperativo que van desde la inequidad hasta las ilegales. Para rectificar la actual situación, si bien se cabe imponer límites legales a la desproporción extrema, más importante resulta afianzar la naturaleza cooperativa, para lo cual es imprescindible que la voluntad de los socios sirva de incentivo y fundamento.

7 «...en comprobaciones realizadas por la Contraloría General de la República, (...) se detectaron cooperativas que el que menos ganaba, ganaba 3000 pesos, y el presidente 37000 pesos, catorce veces más» (Murillo Jorge 2017).

8 «Fíjense, no regulamos el ingreso, porque las cooperativas pagan anticipo y distribuyen utilidades. Si la cooperativa tiene mucho ingreso, y puede repartir un nivel de ingreso alto, no se limita» (Murillo Jorge 2017). 


\section{A modo de conclusiones}

De lo dicho hasta aquí, puede concluirse que:

- El principio de "participación económica de los asociados» ha sido asumido por la legislación cooperativa en Cuba, aunque su implementación se ha caracterizado por la dispersión por formas cooperativas y por la insuficiente regulación, aspecto que ha merecido especial atención a raíz del experimento de las CNA.

- Si bien las normas generales de las CNA son las que mejor regulan el principio en el ordenamiento jurídico cubano, su materialización se ha visto afectada por distintos factores -objetivos y subjetivos - que han dado lugar a conductas desviadas del espíritu cooperativo, las cuales van desde la inequidad hasta las ilegalidades.

- Para superar la situación actual es aconsejable - junto a la previsión de límites legales para conservar la proporcionalidad en la participación económica sobre los retornos por parte de los socios- reorganizar la implementación jurídica de las cooperativas sobre bases coherentes con su identidad, que la orienten hacia la realización de lo colectivo y lo social.

\section{Bibliografía}

Alianza Cooperativa Internacional (ACI). 1995. «Declaración Sobre la Identidad Cooperativa», Manchester, recuperado de http://www.elhogarobrero1905.org.ar, el 12 de diciembre de 2009.

- 2008. "Ley Marco para las Cooperativas de América Latina», San José, recuperado de www.aciamericas.coop, el 18 de diciembre de 2009.

BASTIDAS-DELGADO, Oscar. 2009. "La Especificidad Cooperativa Apuntes para un Cooperativismo Alternativo», Centro de Estudios de la Participación, la Autogestión y el Cooperativismo (CEPAC), Universidad Central de Venezuela.

CANO LÓPEZ, Alfonso. 2008. «El complejo estatuto legal de la cooperativa en España: un apunte sobre algunas líneas de tendencia». Internacionalización de las cooperativas. Aspectos jurídicos, económicos geográficos y sociológicos; Ed. Tirant Lo Blanch, Valencia: pp. 71-88.

CASTRO, Y. \& otros. 2015. "Cooperativas no Agropecuarias en Cuba: salto con obstáculos». Periódico Granma. 8 de mayo. Recuperado de http:// www.cubainformacion.tv/index.php/economia/62594-cooperativasnoagropecuarias-en-cuba-salto-con-obstaculos, el 13 de mayo de 2015.

Comisión De Asuntos Económicos De La Asamblea Provincial Del Poder Popular En Pinar Del Rio. 2016. Estudio sobre el Desarrollo del Sector no Estatal 
en la Provincia y sus impactos en el nivel y calidad de vida de la población, facilitado al autor por Efraín Echevarría, Presidente de esta Comisión.

FERNÁNDEZ PEISO, León Avelino. 2005. El fenómeno cooperativo y el modelo jurídico nacional. Propuesta para la nueva base jurídica del cooperativismo en Cuba, Tesis presentada en opción al Grado Científico de Doctor en Ciencias Jurídicas, Cienfuegos.

GARCÍA MÜLLER, Alberto. 2016. Derecho Cooperativo y de la Economía Social y Solidaria. Asociación Iberoamericana de Derecho Cooperativo, Mutual y de la Economía Social y Solidaria. Mérida.

KAPLAN DE DRIMER, Alicia. 2000. "Las cooperativas ante los peligros de "Desnaturalización" y "Desmutualización"». Anuario de Estudios Cooperativos, Universidad de Deusto, Bilbao: 167-176.

MARTÍNEZ HERNÁNDEZ, Luis. 2015. "Raúl: "Lo que hacemos debe ser sometido constantemente a la crítica constructiva por parte de todos"», Periódico Granma, 1 de junio, recuperado de http://www.granma.cu/ cuba/2015-05-31/raul-lo-que-hacemos-debe-ser-sometido-constantemente-a-la-critica-constructiva-por-parte-de-todos, el 1 de junio de 2015.

MURILLO JORGE, Marino. 2017. «Intervención del miembro del Buró Político del Comité Central del Partido Comunista de Cuba y Jefe de la Comisión de Implementación y Desarrollo, en el X Periodo Ordinario de Sesiones de la VIII Legislatura de la Asamblea Nacional del Poder Popular, en el Palacio de Convenciones». Periódico Granma. 21 de diciembre, recuperado de http://www.granma.cu/cuba/2017-12-22/los-problemas-que-hemos-enfrentado-en-la-actualizacion-son-mas-complejos-y-mas-profundos-que-loque-habiamos-pensado-22-12-2017-02-12-01, el 22 de enero de 2018.

NOVA GONZÁLEZ, Armando. 2012. "Las cooperativas agropecuarias en Cuba: 1959-presente». En Piñeiro Harnecker, C. (compiladora). 2012. Cooperativismo y Socialismo. Una mirada desde Cuba. Ed. Caminos, La Habana: 321-336.

PÉREZ DÍAZ, O. L. 2014. «Seminario para los Notarios sobre los Requisitos Formales para la Constitución de Cooperativas de Primer Grado», Dirección de Notarías y Registros Civiles del Ministerio de Justicia.

PIÑEIRO HARNECKER, Camila. 2014. «Diagnóstico preliminar de las cooperativas no agropecuarias en La Habana, Cuba». Recuperado de https:// www. ceec.uh.cu/file/569/download?token=VfqEKMZE, el 18 de abril de 2016.

RODRÍGUEZ MUSA, Orestes. 2017. La constitucionalización de la cooperativa. Una propuesta para su redimensionamiento en Cuba. Coletânea IBECOOP, No. 1, Ed. Vincere Asociados, Brasilia-DF.

RODRÍGUEZ MUSA, Orestes y Rivera Gort, Julio José. 2015. «Historia y realidad jurídica de la cooperativa en Cuba. Aproximación desde la experiencia práctica a las noveles Cooperativas no Agropecuarias en Pinar del Río». Boletín de la Asociación Internacional de Derecho Cooperativo, No. 49, Universidad de Deusto, Bilbao: 195-222.

TRISTÁ ARBEZÚ, Grisel. 2015. «Cooperativas no Agropecuarias», conferencia ofrecida y reproducida a militantes del Partido Comunista de Cuba por la Comisión de Implementación de los Lineamientos del Partido y la Revolución. 
VUOTTO, Mirta. 2015. «Las cooperativas no agropecuarias y la transformación económica en cuba: políticas, procesos y estrategias», REVESCO. Revista de Estudios Cooperativos, recuperado de http://dx.doi.org/10.5209/rev_ REVE.2016.v120.49697, el 18 de abril de 2016.

VI Congreso del Partido Comunista de Cuba. 2011. Lineamientos de la Política Económica y Social del Partido y la Revolución, aprobados el 18 de abril, recuperado de http://www.prensa-latina.cu/Dossiers/LineamientosVICongresoPCC.pdf

VII Congreso del Partido Comunista de Cuba. 2016-a. Conceptualización del Modelo Económico y Social Cubano de Desarrollo Socialista, recuperado de http://www.cubadebate.cu/wp-content/uploads/2016/05/Conceptualizacion-Modelo-Economico-Social-Cubano-Desarrollo-Socialista.pdf, el 15 de junio de 2016.

- 2016-b. Actualización de los Lineamientos de la Política Económica y Social del Partido y la Revolución para el período 2016-2021, aprobados además por la Asamblea Nacional del Poder Popular en julio del propio año, recuperado de http://www.cubadebate.cu/especiales/2016/09/13/veael-texto-integro-de-la-actualizacion-de-los-lineamientos-para-el-periodo2016-2021-pdf/, el 2 de octubre de 2016.

- 2016-c. Plan nacional de desarrollo económico y social hasta 2030: Propuesta de visión de la nación, ejes y sectores estratégicos, recuperado de http://www.cubadebate.cu/noticias/2016/04/17/informe-central-al-vii-congreso-del-partido-comunista-cuba/, el 18 de abril de 2016.

Cuba Debate: Autoridades explican nuevas medidas respecto a cooperativas no agropecuarias, recuperado de http://www.cubadebate.cu/ noticias/2017/08/09/autoridades-explican-nuevas-medidas-respecto-a-cooperativas-no-agropecuarias/\#.WcVnV8Zx3IU, el 2 de octubre de 2017.

\section{Legislación}

Constitución de la República de Cuba, reformada por la Ley de Reforma Constitucional. Gaceta Oficial de la República de Cuba N. ${ }^{\circ} 10$ Extraordinaria de 16 de julio de 2002.

Ley No. 95. Ley de Cooperativas de Producción Agropecuaria y de Créditos y Servicios. Gaceta Oficial Ordinaria de 29 de noviembre de 2002.

Decreto-Ley No. 305. De las Cooperativas No Agropecuarias. Gaceta Oficial No. 53 Extraordinaria de 11 de diciembre de 2012.

Decreto No. 309. Reglamento de las Cooperativas No Agropecuarias. Gaceta Oficial No. 53 Extraordinaria de 11 de diciembre de 2012.

Acuerdo 5454 del 17 de mayo de 2005 del Comité Ejecutivo del Consejo de Ministros, contentivo del «Reglamento General de las Cooperativas de Producción Agropecuaria» y del «Reglamento General de la Cooperativas de Créditos y Servicios». Gaceta Oficial No. 20 de 4 de julio de 2005.

Resolución 574/2012 del Ministerio de la Agricultura, "Reglamento General de las Unidades Básicas de Producción Cooperativa». Gaceta Oficial No. 037 Extraordinaria de 11 de septiembre de 2012. 


\section{Derechos de autor}

El Boletín de la Asociación Internacional de Derecho Cooperativo es una revista de acceso abierto lo que significa que es de libre acceso en su integridad inmediatamente después de la publicación de cada número. Se permite su lectura, la búsqueda, descarga, distribución y reutilización legal en cualquier tipo de soporte sólo para fines no comerciales y según lo previsto por la ley; sin la previa autorización de la Editorial (Universidad de Deusto) o el autor, siempre que la obra original sea debidamente citada (número, año, páginas y DOI si procede) y cualquier cambio en el original esté claramente indicado.

\section{Copyright}

The International Association of Cooperative Law Journal is an Open Access journal which means that it is free for full and immediate access, reading, search, download, distribution, and lawful reuse in any medium only for non-commercial purposes, without prior permission from the Publisher or the author; provided the original work is properly cited and any changes to the original are clearly indicated. 